\title{
A representação do discurso outro: um setor da atividade metalinguageira
}

\author{
Carlos Eduardo Silva PINHEIRO (D \\ Universidade Federal do Ceará (UFC)
}

\section{RESUMO}

Nesta conferência, Jacqueline Authier-Revuz sobrevoa os principais pontos de La Représentation du Discours Autre - Principes pour une description, seu livro recém-publicado. Na ocasião, a pesquisadora questiona a noção tradicional de Discurso Reportado, assumindo que o termo "reportado" implica uma referência temporal anterior ao ato de enunciação em curso e na qual o enunciador poderia se basear para, então, reportar um já-dito. Authier-Revuz argumenta que essa noção tradicional desconsidera a representação linguageira de discursos virtuais e hipotéticos, isto é, de dizeres não realizados ou passíveis de se realizar. Por isso, a estudiosa propõe a noção de Representação do Discurso Outro (RDO) para repensar a instanciação de um outro dizer no discurso, apresentando o caráter lin-

OPEN ACCESS

EDITADO POR Raquel Freitag

AVALIADO POR Doris Arruda Cunha

DATAS

Recebido: 20/07/2020 Aceito: $26 / 09 / 2020$ Publicado: 09/10/2020

COMO CITAR

Pinheiro, C. E. S. (2020). A representação do discurso outro: um setor da atividade metalinguageira. Revista da Abralin, v. 19, n. 2, p. 1-5, 2020. guageiro, linguístico, discursivo e subjetivo desse fenômeno enunciativo. Authier-Revuz defende ainda que a RDO constitui uma parte do campo mais amplo das Heterogeneidades Enunciativas, sistematizado por ela inicialmente na década de 1980.

\section{RÉSUMÉ}

Dans cette conférence, Jacqueline Authier-Revuz survole les points principaux de La Représentation du Discours Autre - Principes pour une description, son livre publié récemment. À cette occasion là, la chercheuse remet en cause la notion traditionnelle de Discours Rapporté, en supposant que le terme « rapporté » impliquerait une référence temporelle antérieure à l'acte d'énonciation en cours sur laquelle l'énoncé pourrait alors se baser pour rapporter un déjà dit. Authier-Revuz soutient que cette notion traditionnelle ne rend pas compte de la représentation linguistique des discours virtuels et hypothétiques, c'est-à-dire des 


\section{REVISTA DA ABRALIN}

dictons non réalisés ou réalisables. La chercheuse propose donc la notion de Représentation du Discours Autre (RDA) afin de repenser l'instanciation d'un autre dire dans le discours, en présentant le caractère langagière, linguistique, discursif et subjectif de ce phénomène énonciatif. AuthierRevuz soutient également que la RDA fait partie du domaine plus large des Hétérogénéités Énonciatives, qu'elle a systématisé initialement aux années 1980 .

\section{PALAVRAS-CHAVE}

Discurso Reportado. Metadiscursividade. Representação do Discurso Outro.

\section{MOTS CLÉS}

Discours Rapporté. Métadiscursivité. Représentation du discours Autre.

A conferência resenhada neste trabalho integra uma série de transmissões ao vivo realizada pela Associação Brasileira de Linguística (Abralin) em seu canal no Youtube, no período de maio a julho de 2020. Em 16 de julho de 2020, às 10h, a pesquisadora Jacqueline Authier-Revuz, professora emérita da Universidade Paris III - Sorbonne Nouvelle, apresentou o caráter linguageiro, linguístico, discursivo e subjetivo da noção de Representação do Discurso Outro (RDO), formulada por ela para repensar a noção tradicional de Discurso Reportado. Na ocasião, participaram as professoras Dra. Dóris de Arruda Carneiro da Cunha (UNICAP), mediadora da conferência, e as professoras Dra. Suzana Leite Cortez (UFPE) e Ms. Isabel Muniz-Lima (UFC), responsáveis pela tradução simultânea do francês para o português.

Sobrevoando algumas questões abordadas em seu livro mais recente, La représentation du discours autre - Principes pour une description, Authier-Revuz discorre sobre a noção de Representação do Discurso Outro (RDO), que é um desenvolvimento recente dos estudos da autora sobre as heterogeneidades enunciativas, que têm sido seu foco de investigação desde os anos 1980. Esta resenha reflete sobre a caracterização da RDO como um fato linguageiro, pois presente em diferentes produções discursivas; linguístico, pois constitui a própria natureza da língua e se manifesta de diversos modos por meio de uma escala de marcação que vai do hipermarcado, como no discurso direto, ao não marcado, como nas alusões; discursivo, pois evidencia as bordas interdiscursivas e a exterioridade interna de todo discurso; e subjetivo, pois coloca em cena um sujeito que produz uma imagem de si por diferença em relação aos outros sujeitos, orientando-se por uma ilusão de domínio sobre as coisas que enuncia que advém do seu imaginário. Finalmente, discute-se o que a pesquisadora apresenta no final da sua conferência ao responder questões do chat. 


\section{REVISTA DA ABRALIN}

Inicialmente, Authier-Revuz aborda o caráter linguageiro da RDO. Para ela, a capacidade de falar sobre si mesma é um privilégio da língua natural humana, pois estranha a outros sistemas de signos. No primeiro capítulo de sua obra recém publicada, a autora exemplifica essa assunção com o estudo de Benveniste, de 1966, sobre a comunicação das abelhas. Para esse autor, a comunicação das abelhas se resume à transmissão de dados objetivos, como direção, distância e tipo de alimento encontrado. Desse modo, as abelhas não são capazes de construir uma mensagem a partir de outra mensagem. Authier-Revuz afirma que não haveria RDO na comunicação das abelhas, pois esse sistema de signos não é capaz de categorizar a si mesmo, como o fazem as línguas naturais humanas.

Por isso, é possível dizer que a reflexividade metalinguística é constitutiva e linguageira, pois o discurso é sempre discurso sobre um discurso, seja o discurso que está se fazendo, seja o discurso de um outro. Isso se dá porque não só a metalinguagem é interna à língua, mas porque, considerando a perspectiva dialógica da linguagem assumida por Authier-Revuz, a língua se constitui pela heterogeneidade de vozes que a atravessam. Portanto, são duas as condições que impedem a língua de ser unívoca: a reflexividade metalinguageira e a alteridade discursiva.

Em função disso, a autora passa a apresentar a geografia do espaço metadiscursivo com o objetivo de delinear o caráter linguístico da RDO. De acordo com Authier-Revuz, a geografia da metalinguagem natural é dividida em duas regiões distintas: a região do discurso metalinguístico sobre a língua e a linguagem (ou types, para usar o termo da autora) e a região do metadiscurso sobre o discurso (ou tokens). Essa segunda região, por sua vez, divide-se em outras duas: a região do metadiscurso sobre o discurso que está se fazendo e a região sobre o discurso do outro.

Assim, resumidamente, a autora propõe três zonas de referência para o metadiscurso: a Zona A, com enunciados que refletem sobre a língua e a linguagem ("Está ensolarado" é uma frase impessoal) ${ }^{1}$, a Zona B, com enunciados que refletem sobre o discurso que está sendo feito (Estou lhe dizendo que ele será eleito) e que são o objeto de análise da Autorrepresentação do Dizer (ARD), e a Zona C, com enunciados que refletem sobre o discurso do outro (Seu grito "Está ensolarado" soou alegremente) e que são o objeto de análise da RDO, foco da discussão proposta por Authier-Revuz.

Estabelecido o lugar da RDO como uma zona particular do espaço mais amplo da geografia metadiscursiva, Authier-Revuz define a RDO como um ato de enunciação que tem como referência um outro ato de enunciação. A autora representa esses dois atos diferentes com a letra "A" maiúscula, para o ato de enunciação principal, e "a" minúsculo, para o ato de enunciação representado. A pesquisadora propõe que a caracterização detalhada do campo da RDO deve levar em consideração três fatores: o estatuto semântico do enunciado representado, que pode ser de objeto do dizer (Jean diz que Marie deu uma longa caminhada) ou fonte do dizer (De acordo com João, Maria deu uma longa caminhada); o estatuto semiótico do enunciado representado, que pode se configurar em discurso ordinário, nos casos em que a palavra do outro é apenas usada pelo enunciador (Segundo ele, eu fiz

1 Os exemplos utilizados nesta resenha foram retirados do handout disponibilizado por Jacqueline Authier-Revuz para a conferência. O documento está disponível em: https://aovivo.abralin.org/wp/wp-content/uploads/2020/07/Hand-out-ABRALIN-16-juillet2020.pdf. 


\section{REVISTA DA ABRALIN}

o que estava certo), ou discurso com autonimização, para os casos em que a palavra do outro é usada e mencionada/mostrada no enunciado ("Fi-lo bem", como diria Marie); e o tipo de articulação das ancoragens enunciativas dos dois atos de enunciação (A/a), que podem funcionar de três formas: ancoragens unificadas dos dois atos de enunciação em A; duas ancoragens distintas em um mesmo ato de enunciação A; e ancoragens partilhadas entre os dois atos de enunciação.

É por meio desses fatores que a autora busca revisitar a noção tradicional de Discurso Reportado, assumindo que essa noção comporta apenas uma parte das formas possíveis de se instanciar o dizer exterior no discurso, a saber, as formas do Discurso Direto (DD), Discurso Indireto (DI) e do Discurso Indireto Livre (DIL). Segundo a pesquisadora, a expressão "reportado" implica uma referência temporal anterior ao ato de enunciação em curso na qual o enunciador poderia se basear para, então, reportar um já-dito. Assim, o Discurso Reportado desconsidera a possibilidade de se representar discursos futuros, ficcionais, que podem ser ditos ou nunca serão ditos.

Assim, Authier-Revuz formula cinco modos pelos quais a Representação do Discurso Outro pode se instanciar discursivamente, quais sejam, a forma do Discurso Direto (DD), como em Ele diz: eu vencerei todos eles!; a forma do Discurso Indireto (DI), como em Ele diz que vai superar todos; a forma do Discurso Indireto Livre (DIL), como em Ele não tem dúvidas: vencerá todos eles!; a forma da Modalização Autonímica de Empréstimo (MAE), como em Segundo ele, ele vai superar a todos; e a forma da Modalização como Asserção Segunda (MAS), como em Espero que ele os "pulverize", como ele gosta de dizer.

Depois de explorar o caráter linguageiro e linguístico da RDO, Authier-Revuz explana de maneira breve o funcionamento discursivo desse campo da geografia metadiscursiva e a noção de sujeito que ele implica. Para ela, estudar a RDO é estudar as bordas que existem entre os discursos, como postula a Análise do Discurso francesa. Assim, o estudo dos modos pelos quais é possível falar da relação entre diferentes discursos é capaz de revelar os diálogos interdiscursivos que constituem a natureza da linguagem. Essa consideração, por sua vez, implica na noção de sujeito assumida por essa proposta teórica. Authier-Revuz, ainda na década de 1980, recorreu ao dialogismo bakhtiniano e à psicanálise freudo-lacaniana, duas abordagens exteriores à linguística, para dar conta da complexa noção de sujeito de sua teoria enunciativa do sentido.

A autora convoca essas duas abordagens não linguísticas argumentando que ambas destituem o sujeito do domínio do seu dizer, pois, enquanto o dialogismo situa o sujeito em uma relação fronteiriça com o exterior, dispondo-o sempre em uma relação constitutiva com o outro, a psicanálise assume a descentração do sujeito e sua clivagem ao inconsciente, colocando-o como efeito de linguagem. A perspectiva assumida por Authier-Revuz é, portanto, a de um sujeito que não domina completamente as palavras que enuncia porque é atravessado por uma dupla alteridade: a discursiva e a do inconsciente. Desse modo, a noção de sujeito da RDO é aquele mesmo das abordagens discursivas, a saber, um sujeito atravessado pelo interdiscurso e clivado pelo inconsciente.

Para a pesquisadora, o sujeito se inscreve nos discursos pela relação de diferença que estabelece com as palavras dos outros, como se fosse senhor de suas palavras e reconhecesse a presença de palavras que não são suas. Todavia, as formas de RDO manifestam uma negociação do sujeito com a alteridade que o atravessa e a qual ele não consegue escapar. Assim, essas formas terminam 


\section{REVISTA DA ABRALIN}

constituindo, na verdade, uma máscara de vidro, porque elas revelam mais do que escondem. Esta negociação do sujeito com a alteridade evidencia a tentativa de disfarçar com ataduras a ferida exposta - a heterogeneidade constitutiva -, sem eliminá-la do caminho enunciativo.

Finalizando sua fala, ao responder questões do chat, Authier-Revuz esclareceu ainda que RDO constitui uma parte do campo mais amplo das Heterogeneidades Enunciativas, sistematizado por ela inicialmente na década de 1980 (cf. AUTHIER-REVUZ, 1982; 1984). A autora também defendeu a possibilidade da existência de outros modos de RDO para além dos que ela sistematizou. A pesquisadora argumenta que a evolução das formas e dos modos de usar a língua permitidas pelos meios digitais pode vir a constituir novos modos de representar discursivamente a fala dos outros. Por último, Authier-Revuz enfatizou que, mesmo não sendo senhor das próprias palavras que enuncia, o sujeito tem uma ilusão necessária desse controle, que é da ordem do imaginário. Assim, o sujeito faz tentativas de ultrapassar esse estado de urgência para o controle de si e do outro pela restauração da univocidade de seu dizer. Ocorre que essas tentativas são uma ilusão instaurada no imaginário do falante como parte integrante da atividade enunciativa.

\section{REFERÊNCIAS}

AUTHIER-REVUZ, Jacqueline. Hétérogénéité montrée et hétérogénéité constitutive, éléments pour une approche de l'autre dans le discours. DRLAV, v. 26, 1982. p. 91-151.

AUTHIER-REVUZ, Jacqueline. Hétérogénéités énonciatives. Langages, v. 73, 1984. 98-111.

AUTHIER-REVUZ, Jacqueline. La Représentation du Discours Autre. Berlin/Boston : De Gruyter, 2020.

BENVENISTE, Émile. Problèmes de linguistique générale I. Paris: Gallimard, 1966.

REVISITER le «Discours Rapporté »: la réflexivité métalangagière au cœur de l'énonciation - enjeux langagiers, linguistiques, discursifs, subjectifs de la Représentation du Discours Autre. Conferência apresentada por Jacqueline Authier-Revuz [s.l., s.n], 2020. 1 vídeo (1h 58min 25s). Publicado pelo canal da Associação Brasileira de Linguística. Disponível em: https://www.youtube.com/watch?v=t4giw aRnes\&t=2472s. Acesso em: 15 jul. 2020. 